\title{
SURGICAL CORRECTION OF MITRAL INCOMPETENCE RESULTING FROM BACTERIAL ENDOCARDITIS
}

\author{
BY \\ B. G. BARRATT-BOYES \\ From Green Lane Hospital, Auckland, New Zealand
}

Received March 27, 1962

The surgical correction of mitral incompetence by internal reconstruction of the valve ring and the cusps has proved disappointing (Effler et al., 1958; Merendino et al., 1959) and has been followed by attempts at partial or total valve replacement (Braunwald, Cooper, and Morrow, 1960). While our experience with internal reconstructive procedures in patients with severe rheumatic mitral incompetence, with or without some degree of stenosis, has also proved unsatisfactory with a failure rate of about 50 per cent, more encouraging results have been obtained in patients with mitral incompetence following bacterial endocarditis. It seems that these patients are relatively favourable candidates for simple reconstruction of the valve. Three such cases are here reported.

\section{CASE REPORTS}

Case 1. This patient, a housewife of 39 years, had a septic abortion in November 1957, following which blood cultures yielded a coagulase positive Staphylococcus aureus: mitral systolic and diastolic murmurs were heard and mild congestive failure appeared. The infection was cured by penicillin and when the patient was discharged from hospital in April 1958 her tendency to congestive heart failure was satisfactorily controlled by digitalis alone. During the next six months her cardiac state gradually deteriorated with increasing dyspnœa on exertion, orthopnœa, and recurrent attacks of paroxysmal nocturnal dyspnœa. By the end of 1958 the patient was a cardiac invalid, and remained so during the next two years despite intensive treatment in hospital. During this time there was intermittent congestive heart failure but sinus rhythm was maintained.

Clinical findings included a widespread præcordial impulse extending from cardiac apex to sternum. On auscultation the apical first sound was diminished, and was accompanied and followed by a pansystolic murmur. An apical third heart sound was followed by a short high-pitched mid-diastolic murmur. There were no tricuspid or aortic murmurs. The chest radiograph (Fig. 1) on October 13, 1960, showed cardiac enlargement with a cardiothoracic ratio of 0.58 : fluoroscopy showed enlargement of left ventricle and left atrium but mitral valve calcification was not seen. The electrocardiogram showed P mitrale and ST depression with $T$ inversion in left ventricular surface leads and their equivalents, these changes being consistent with hypertrophy of the left atrium and moderate left ventricular hypertrophy in addition to digitalis effect.

Operation under heart-lung bypass was undertaken on December 20, 1960, through a right posterolateral thoracotomy. The left atrium was moderately enlarged and was entered through a vertical incision placed just medial to the point of entry of the right pulmonary veins. The left heart was evacuated using two suction lines which returned blood to the venous reservoir of the machine. Exposure of the mitral valve revealed a normal-sized valve ring and the valve cusps which were normal except at the periphery of the two commissures. At the postero-medial commissure about $0.5 \mathrm{~cm}$. from the ring there was a deficiency in the free edge of the anterior cusp where there was a notch, $0.5 \mathrm{~cm}$. deep, with slight thickening of the surrounding cusp tissue. Adjacent to the notch were several prominent tags of tissue probably representing organized vegetations. Remnants of a ruptured chorda were seen, one projecting from beneath the valve edge and the other from the apex of the inferior papillary muscle. It was clear that the regurgitation was 


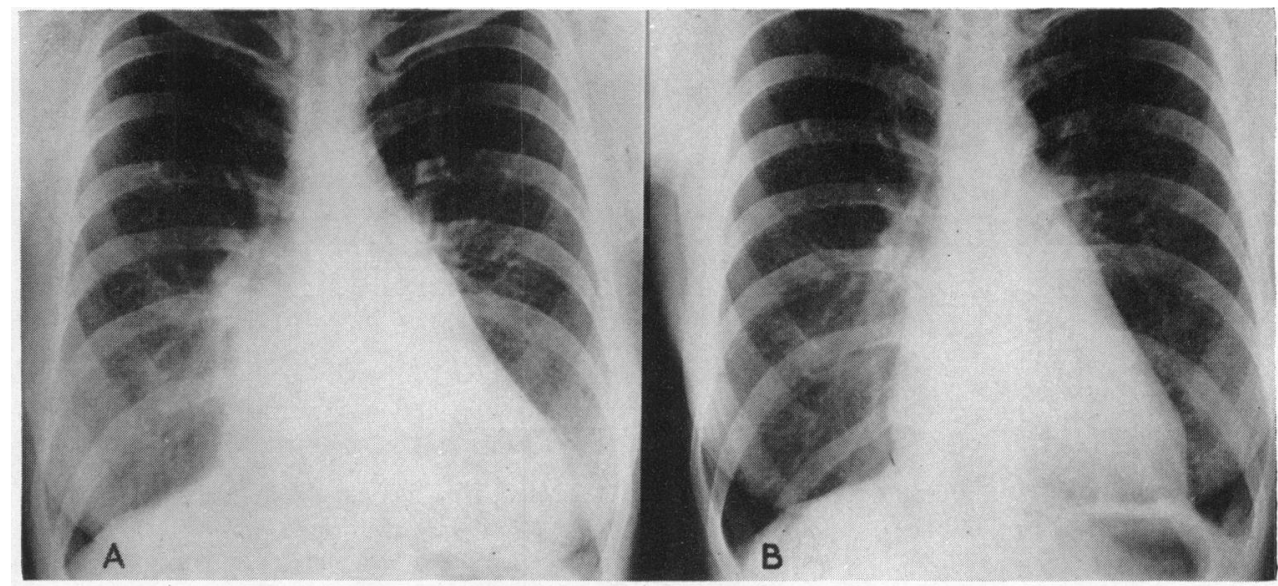

FIG. 1.-Case 1. Postero-anterior radiographs of the chest (A) before operation (October 13, 1960), and (B) nine months after operation (September 28, 1961).

occurring at this commissure. At the opposite antero-lateral commissure both cusps were fused for a distance of approximately $0.5 \mathrm{~cm}$. and there was moderate cusp thickening and matting of the subjacent chordæ. While the changes at the posterior commissure were thought to result from infective endocarditis, those at the anterior commissure were typical of healed rheumatic endocarditis. By the use of interrupted silk sutures to approximate the edges of the two cusps and by including the deficiency in the anterior cusp within this suture line the posterior commissure was obliterated over a distance of $0.7 \mathrm{~cm}$. and surgical correction of the incompetence was achieved. A knife was then used to open the fused anterior commissure to the valve ring and to split vertically the underlying papillary muscle. The valve orifice then admitted two fingers $(3.5 \mathrm{~cm}$.) and full mobility appeared to have been restored. Examination of the function of the valve after the left ventricle had been allowed to fill confirmed almost complete abolition of the incompetence, and the atrial incision was closed. Ventricular contraction was particularly vigorous throughout and doubts were felt as to whether all air had been excluded from the left heart. However, when heart-lung bypass was stopped the heart took over without incident and the patient awoke almost immediately after closure of the thoracotomy incision. The early post-operative course was uneventful with recovery of full consciousness during the first few hours; but thereafter the patient became confused and semi-comatose, a left hemiparesis appeared and soon afterwards there were several epileptiform convulsions. These were controlled by intravenous sodium gardenal and intramuscular paraldehyde. An infusion of urea in invert sugar (1.5 mg. per kg. body weight) was given and this was repeated some ten hours later. The patient's condition rapidly improved and by the second day after operation she was fully conscious. Speedy recovery from the hemiplegia followed and there was full return of higher mental faculties. During this time, as during further hospital convalescence, the cardiac condition was satisfactory and, although maintenance digitalis was continued, neither sodium restriction nor diuretics were necessary. At the time of discharge three months after operation the systemic venous pressure was normal and the patient was no longer orthopnœic. Although there was still an apical pansystolic murmur the præcordial impulse was not overactive and at the apex there was neither a third heart sound nor a mid-diastolic murmur. When seen ten months later the patient had only slight effort intolerance, and the heart size was almost normal (Fig. 1) in September 1961. The physical signs were the same as those at the time of discharge.

Case 2. In this patient, a 22-year-old law student, who showed the features of Marfan's syndrome, a heart murmur had been noted soon after birth. When 8 years old he had rheumatic fever. Subsequently he had remained well with a normal effort tolerance until December 1960, when he was admitted to hospital elsewhere because of sudden onset of fever. Blood cultures grew Streptococcus viridans and treatment for bacterial endocarditis was instituted and continued for five weeks. During this time he developed congestive heart failure which was controlled by digitalis and diuretics. After the infection was cured he remained in incipient congestive heart failure despite these measures, and was referred to this unit in February 1961, for consideration of surgical treatment. Examination at this time revealed slightly 


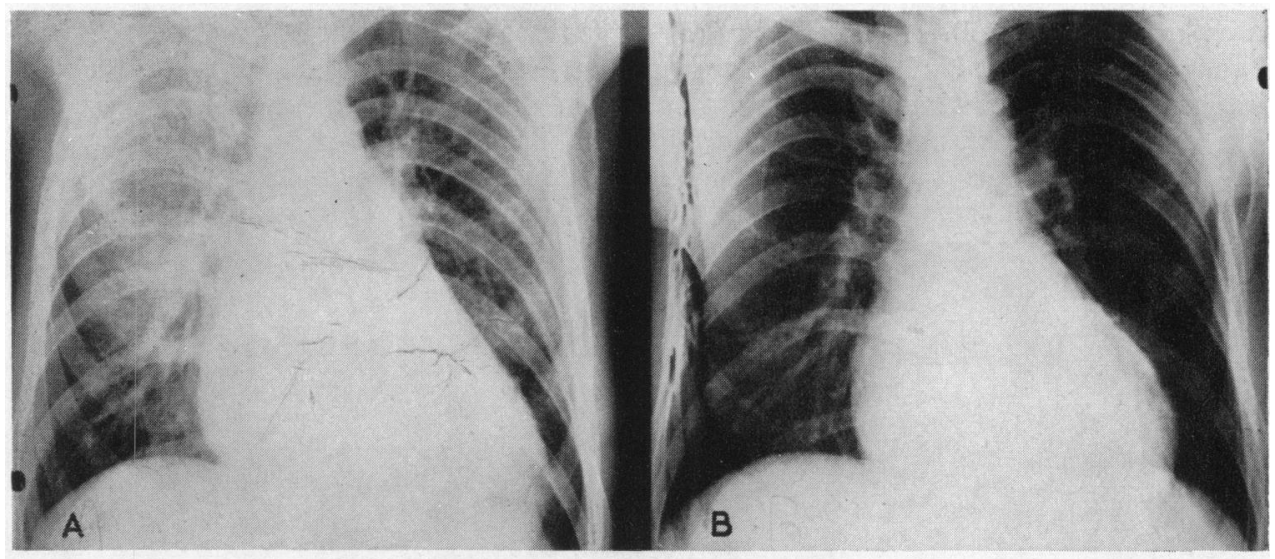

FIG. 2.-Case 2. Postero-anterior radiographs of the chest (A) immediately before operation (May 1, 1961), and (B) eight weeks later (June 26, 1961).

raised venous pressure and a persistent sinus tachycardia of about 120 a minute with frequent ectopic beats. A præcordial bulge caused asymmetry of the chest. The heart was overactive and the apex beat was in the anterior axillary line in the fifth intercostal space. At the apex the first heart sound was diminished and there was a loud pansystolic murmur followed by a mid-diastolic murmur of slight to moderate intensity and duration. Chest films (Fig. 2) and fluoroscopy showed cardiomegaly with a cardiothoracic ratio of $0 \cdot 61$, and enlargement of left ventricle and left atrium. The cardiogram, which showed $P$ mitrale, considerable left ventricular hypertrophy ( $R$ in V5=40 mm.), ST depression, and low voltage of $T$ in left ventricular surface leads, matched the radioscopic findings.

The history of a murmur dating from birth suggested the possibility of congenital mitral incompetence in association with Marfan's syndrome, but in view of the history of rheumatic fever the possibility of further valve damage resulting from this cause arose. Whatever the nature of the initial lesion, however, there seemed no real doubt that the development of severe mitral incompetence had coincided with the attack of bacterial endocarditis which had resulted in either further cusp destruction or rupture of a chorda. In spite of some improvement through medicinal measures and weight reduction the patient remained breathless on the slightest exertion and subject to occasional attacks of paroxysmal nocturnal dyspnœa. An attempt at surgical correction was therefore recommended.

At operation under heart-lung bypass in May 1961, the heart was exposed by a right postero-lateral thoracotomy. Both atria were moderately dilated but it was necessary to develop the interatrial groove in order to gain access to the left atrium in front of the right pulmonary veins. Exposure of the mitral valve failed to reveal significant distortion or thickening of either cusp. Both commissures were fully open and the mitral valve ring was not dilated. Adjacent to the antero-lateral commissure, however, the anterior mitral cusp was completely flail due to rupture of the major chorda attaching this portion of the cusp to the superior papillary muscle. The tip of the valvular remnant of the ruptured chorda presented as a localized irregular and partially calcified nodule $2.5 \mathrm{~mm}$. across, which was no doubt a residuum of the bacterial infection. To correct the incompetence the ruptured chorda and the adjacent free edge of the anterior cusp were sutured down to the apex of the superior papillary muscle with two fine silk sutures. As the normal chordæ still present in this region were relatively short and as the anterior cusp was freely mobile and voluminous, this did not seem to restrict the movement of the anterior cusp. Inspection of valve function after the left ventricle had been allowed to fill revealed almost complete abolition of the incompetent jet. Exit was then made from the atrium, the aorta being cross-clamped for five minutes to arrest the heart and thus aid in exclusion of air from the left heart chambers. When heart-lung bypass was stopped the heart took over the circulation without incident. The patient's post-operative course was uneventful apart from a phase of paroxysmal atrial fibrillation which began on the ninth day after operation and persisted for three weeks before spontaneous reversion to sinus rhythm. During the post-operative course maintenance digitalis was continued but there was no evidence of congestive heart failure and neither sodium restriction nor diuretic treatment was required. Eight weeks after operation the chest radiograph showed 
reduction in heart size (Fig. 2). At the time of discharge three months after operation the clinical findings incluced a moderately overactive left ventricular apex beat which had by then, however, returned to the mid-clavicular line, and a faint late systolic murmur and faint third heart sound at the apex. When the patient was reviewed five months later he had resumed all normal activities short of competitive sport, and had not experienced undue effort dyspnœa. On examination the apical third heart sound was no longer audible though the other findings were essentially the same as those at the time of discharge. The chest radiograph indicated further reduction in heart size.

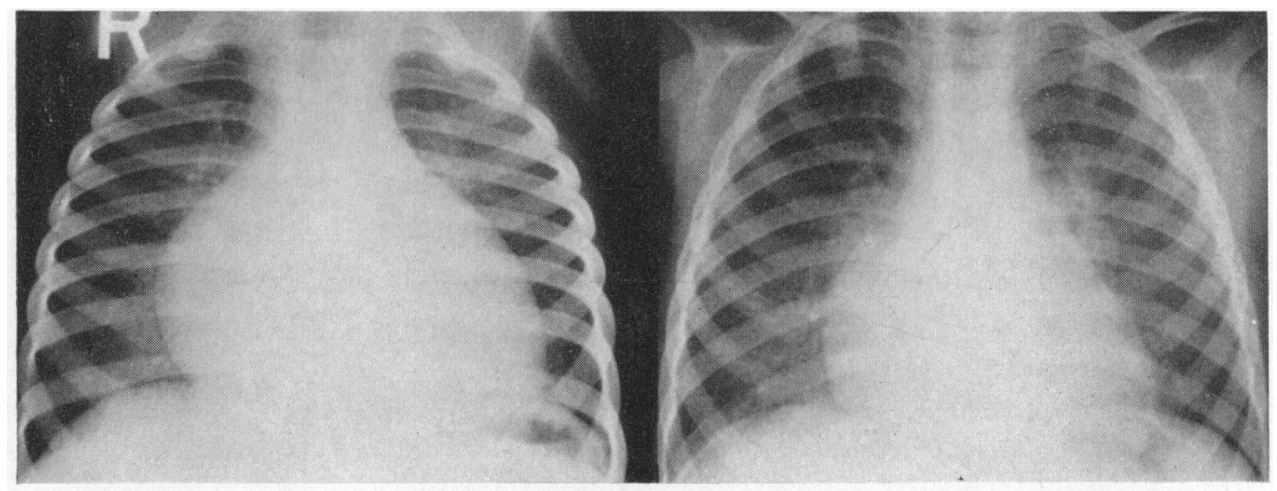

FIG. 3.-Case 3. Postero-anterior radiographs of the chest before operation (June 7, 1961), and seven weeks after operation (August 12, 1961).

Case 3. This male child aged 34 months had been an apparently normal infant and at the age of 20 months had developed an abscess behind the right ear, which required incision. At this time physical examination was otherwise normal and no cardiac murmurs were noted. Eight months later he suddenly developed fever and meningism. A group A streptococcus was cultured from the cerebrospinal fluid and antibiotic treatment was commenced. Eight days later an apical systolic murmur was heard for the first time, but the heart was not enlarged. Four weeks after the onset of this illness embolism occurred in the right brachial artery and in a cerebral vessel with resultant right hemiplegia. The cardiac condition rapidly worsened with enlargement and severe congestive heart failure. Blood cultures yielded a coagulase positive Staphylococcus aureus. During the next two months the child remained in a critical condition but gradual improvement followed intensive antibiotic treatment, and in April 1961 antibiotics were stopped. The patient was transferred to this unit a fortnight later, at which time, despite medicinal treatment, he remained in severe congestive heart failure. He was morose, thin, and wasted. The right radial pulse was absent and there was paresis of the right arm and leg with a moderate degree of flexion contracture of the right knee. Examination of the cardiovascular system revealed sinus rhythm with a poorly sustained small volume pulse and blood pressure of $105 / 70 \mathrm{~mm}$. Hg. There was an overactive left ventricle, with the apex displaced to the anterior axillary line in the fifth left intercostal space. Auscultation revealed a loud musical pansystolic murmur at the apex where there was also a mid-diastolic murmur of moderate intensity and duration. The chest radiograph (Fig. 3) showed cardiac enlargement with a cardiothoracic ratio of 0.75 and widening of the subcarinal angle arguing for left atrial enlargement. The electrocardiogram was consistent with biatrial and biventricular hypertrophy, the left ventricle predominating. A diagnosis of severe mitral incompetence and functional tricuspid incompetence secondary to congestive heart failure was made. Little improvement followed intensive medical treatment and it was decided, therefore, that despite his small size, $26 \mathrm{lb}$. (11.8 $\mathrm{kg}$.$) , an attempt at surgical correction was warranted.$

On June 29, 1961, with the aid of heart-lung bypass, operation was undertaken through a right posterolateral thoracotomy. Both atria were enlarged, but in order to gain easy access to the left atrium in front of the right pulmonary veins it was necessary to develop the interatrial groove. On exposing the mitral valve the chordæ were found to be normal, as was the posterior mitral cusp. The mitral valve ring was not dilated but, adjacent to the antero-lateral commissure, the anterior cusp was considerably thickened and within this area there was a punched-out hole $4 \mathrm{~mm}$. in diameter. This defect was readily closed with three 
interrupted silk sutures. As it appeared that this abolished the mitral incompetence nothing further was done to the valve. During closure of the left atrial incision the aorta was cross-clamped to produce temporary cardiac arrest as an aid to excluding all air from the left heart chambers. When bypass was terminated the heart took over without incident.

The child's immediate post-operative course was completely uncomplicated and during the first week there was a dramatic fall in jugular venous pressure to near normal levels. The patient developed a voracious appetite and by the time of discharge, some seven weeks after operation, he had gained approximately $6 \mathrm{lb}$. $(2.7 \mathrm{~kg}$.) in weight. At this time he was free from signs of failure while on maintenance dosage of digitalis without either sodium restriction or diuretics. Auscultation revealed only a faint apical systolic murmur, and the chest radiograph (Fig. 3) showed that the heart size had returned nearly to normal. At review examination five months later the child was vigorous and healthy and of average weight for age. The physical findings were similar to those at the time of discharge and both the chest radiograph and the cardiogram were within normal limits.

\section{Discussion}

Bacterial endocarditis on the mitral valve produces severe incompetence by creating a deficiency in the body or edge of the cusp, by weakening the valve chordæ with ultimate chordal rupture, or by a combination of these two mechanisms. Pre-existing congenital valve deformity or rheumatic valve disease may add to the changes but if valve function is not significantly abnormal before the endocarditis, such additional lesions need not mitigate against a successful surgical correction of the incompetence. In the three patients reported here, two with probable preceding rheumatic valve disease, almost complete correction of the mitral incompetence was achieved simply, either by closing a deficiency in the body or edge of the cusp or by reattaching the flail portion of the cusp to the appropriate papillary muscle within the ventricle. No foreign material other than silk sutures remained in the heart, and as the mitral annulus was not dilated additional plication of the ring was not required. Each of these patients has improved conspicuously and, although in all the apical systolic murmur remains, there is nothing to suggest that any residual mitral incompetence is of hæmodynamic significance. From these results it appears that mitral incompetence secondary to bacterial endocarditis has a more favourable surgical prognosis than rheumatic mitral incompetence.

Several points in the technique of open operation of a mitral valve using a high flow normothermic perfusion deserve mention. First, the field must be completely free of blood to allow accurate examination of the valve cusps and chordae, and for this purpose an efficient open heart return system such as that described elsewhere (Barratt-Boyes and Yarrow, 1961) using two open heart lines is essential. The left atrial cannula tip is tucked into the orifice of the left pulmonary veins and the metal "coronary sinus" sucker is passed through the valve to lie in the apex of the left ventricle. Once the field is clear of blood there may still be difficulty in examining the ventricular aspect of the valve cusps, especially when the ventricle is contracting vigorously, for these structures lie deep in the operating field, and the cusps are difficult to grasp with conventional tissue forceps. This problem has been solved effectively by the use of two strong long-handled blunt hooks that serve admirably to hook up the valves for detailed examination. Another difficulty relates to the evacuation of air from the left heart chambers after the repair has been completed (Kay et al., 1958). This may prove impossible when the ventricle is contracting vigorously and for this reason it is now routine practice to cross-clamp the aorta during closure of the atriotomy so that ventricular contraction temporarily ceases and air can be massaged carefully from beneath the valve cusps and from the various crevices within the left ventricle and atrium. Undoubted delayed air embolism occurred in Case 1 in this series where this was not done, but since adopting the above routine this complication has not occurred in subsequent similar operations.

\section{SUMMARY}

Three patients with severe mitral incompetence resulting from bacterial endocarditis have been successfully treated surgically by simple reattachment of ruptured chordæ or by mitral valvuloplasty 
with the aid of heart-lung bypass. Incorporation of foreign bodies or plication to the valve ring was not required.

The pathology of mitral incompetence secondary to bacterial endocarditis is discussed and it is concluded that such patients are relatively favourable candidates for surgical correction. Various points in surgical technique are emphasized.

My special thanks are due to Dr. J. B. Lowe and Dr. R. D. Rowe for the medical management of these patients.

\section{REFERENCES}

Barratt-Boyes, B. G., and Yarrow, S. (1961). Aust. N.Z.J. Surg., 30, 260.

Braunwald, N. S., Cooper, T., and Morrow, A. G. (1960). J. thorac. cardiovasc. Surg., 40, 1.

Effler, D. B., Groves, L. K., Martinez, W. V., and Kolff, W. J. (1958). J. thorac. cardiovasc, Surg., 36, 665.

Kay, E. B., Nogueira, C., Head, L. R., Coenen, J. P., and Zimmerman, H. A. (1958). J. thorac. cardiovasc. Surg., 36, 677.

Merendino, K. A., Thomas, G. I., Jesseph, J. E., Herron, P. W., Winterscheid, L. C., and Vetto, R. R. (1959). Ann. Surg., 150, 5. 